\title{
BMJ Open Prevalence and predictors of birth preparedness and complication readiness in the Kassena-Nankana district of Ghana: an analytical cross- sectional study
}

Mahama Saaka (D) , ${ }^{1}$ Lawal Alhassan ${ }^{2}$

To cite: Saaka M, Alhassan L. Prevalence and predictors of birth preparedness and complication readiness in the Kassena-Nankana district of Ghana: an analytical crosssectional study. BMJ Open 2021;11:e042906. doi:10.1136/ bmjopen-2020-042906

- Prepublication history for this paper is available online. To view these files, please visit the journal online (http://dx.doi org/10.1136/bmjopen-2020042906).

Received 18 July 2020 Revised 25 February 2021 Accepted 03 March 2021
Check for updates

(C) Author(s) (or their employer(s)) 2021. Re-use permitted under CC BY-NC. No commercial re-use. See rights and permissions. Published by BMJ.

${ }^{1}$ Nutritional Sciences, University for Development Studies, Tamale, Ghana

${ }^{2}$ Nutrition Unit, Ghana Health Service, Bawku West, Bawku, Ghana

Correspondence to Dr Mahama Saaka; mmsaaka@gmail.com

\section{ABSTRACT}

Objectives To assess birth preparedness and complication readiness (BPACR) and associated factors among mothers who had given birth in the past 12 months prior to the study.

Design An analytical cross-sectional study.

Setting The study was carried out in the rural areas of Kassena-Nankana district located in the Upper East Region of Ghana.

Participants The study population comprised 600 postpartum women who had delivered within the last 12 months prior to the study.

Primary outcome measure The primary outcome measure was BPACR.

Results The prevalence of BPACR among recently delivered women was very low as less than $15 \%$ were able to mention at least three of the five basic components of birth preparedness/complication readiness that were fulfilled. After adjustment for confounding effect using multivariable logistic regression analysis, high educational level (adjusted OR (AOR)=3.40 (95\% Cl: 1.88 to 6.15)), better knowledge about obstetric danger signs during pregnancy (AOR=4.88 (95\% Cl: 2.68 to 8.90)), older women ( $\geq 35$ years) ( $\mathrm{AOR}=2.59$ (95\% Cl: 1.11 to 6.02$)$ ), women of low household wealth index (AOR=4.64 $(95 \%$ $\mathrm{Cl} 1.97$ to 10.91)) and women who received lower content of antenatal care services (AOR=3.34 (95\% Cl: 1.69 to 6.60)) were significant predictors of BPACR.

Conclusion This study concludes that BPACR practices were low. High educational attainment of the woman, having adequate knowledge about obstetric danger signs during pregnancy, older women ( $\geq 35$ years) and women of low household wealth index were significant predictors of BPACR. The predictors identified should be given high priority by health authorities in addressing low prevalence of BPACR.

\section{INTRODUCTION}

The WHO estimated that maternal mortality ratio (MMR) in low-income countries in 2017 was 462 per 100000 live births versus 11 per 100000 live births in high-income countries. ${ }^{1}$ Pregnant women continue to die needlessly
Strengths and limitations of this study

- Little or no information is currently available on levels of birth preparedness and complication readiness (BPACR) in Ghana and specifically in Upper East Region.

- A major strength of this study is that it involved large sample size and a validated questionnaire of birth preparedness/complication readiness index developed by Johns Hopkins Program for International Education in Gynecology and Obstetrics (JHPIEGO) was used.

- Being a cross-sectional survey study, it was not possible to draw causal conclusions.

- Some responses were self-reported and therefore subjected to information measurement bias.

from preventable causes in sub-Saharan Africa $^{2-5}$ and one of the reasons for this situation is inadequacy or lack of birth and emergency preparedness. ${ }^{6}$

The causes of maternal morbidity and mortality has been attributed to delays in seeking care, reaching care and in receiving adequate care when reaching a health facility. ${ }^{7}$ This model of delay is based on the assumption that knowledge of danger signs and preparedness for addressing obstetric complications makes it possible to promptly identify and address delay in accessing skilled delivery services. ${ }^{8}$

Enhancing utilisation of maternal health services and increasing access to skilled care during childbirth, particularly for women with obstetric complications is best achieved through improved knowledge of obstetric danger signs, birth preparedness practices and readiness for emergency complications. ${ }^{9} 10$ Birth preparedness and complication readiness (BPACR) helps ensure that pregnant women receive skilled delivery care 
without delays by encouraging them, their families and communities to effectively plan for births and deal with obstetric complications, if they occur. ${ }^{11} 12$ The concept of BPACR for a woman includes identifying a skilled attendant/health facility with delivery services, making transportation plans, saving money and identifying a blood donor. $^{13}$

Several studies across the world suggest that promoting BPACR interventions improves preventive behaviours, improves knowledge of mothers about danger signs and leads to improvement in care-seeking during obstetric emergency. ${ }^{14-18}$ Furthermore, evidence from a metaanalysis of 14 randomised studies showed that BPACR interventions, are effective in reducing maternal and neonatal mortality in low-resources setting. ${ }^{19}$ The effect of this intervention largely varies ${ }^{2021}$ depending on study setting and population.

Ghana is one of the sub-Saharan African countries with a high MMR of 314 maternal mortalities per 100000 live births as of $2016 .{ }^{1}$

Though the benefits of BPACR have been documented in several countries, little or no information is currently available on levels of BPACR in Ghana and specifically in Upper East Region where the prevalence maternal death is relatively higher than the national average. The aim of the present paper, therefore, was to assess BPACR and associated factors among mothers who had given birth in the past 12 months prior to the study in the Upper East Region of Ghana. Hopefully, the findings of the study may be useful in the design of effective programmes and interventions to improve maternal and neonatal health.

\section{METHODS AND ANALYSIS \\ Study setting}

The study was carried out in the Kassena-Nankana municipality which is 1 of the 13 districts in the Upper East Region of Ghana. The municipality has an estimated population of 116700 with a population density of 102 persons per square kilometre which is served by 1 municipal hospital, 2 health centres and 19 functioning community-based health planning and services zones (KNMA, 2010). Agriculture is the mainstay of the local economy and accounts for about $68 \%$ of the employable population.

\section{Study design, population and sampling}

A community-based cross-sectional study design was used. The primary study population comprised women of reproductive age (15-49 years) who delivered within the last 12 months.

A sample size of 630 was estimated using single population proportion formula with the assumption of $95 \%$ confidence level, $5 \%$ margin of error and proportion of women who had adequate birth preparedness/complication readiness (BPCR) being 50\%. The sample size factored in a design effect of 1.5 and an additional $10 \%$ to take care of non-responses, damaged or incomplete questionnaires.

A two-stage probability proportionate to size sampling methodology was used to select 30 clusters from the list of communities in the district. In the first stage, all communities with their respective populations in five randomly selected submunicipalities were first fed into an Emergency Nutrition Assessment for SMART 2011 software to randomly generate the clusters within which the households were selected. In the second stage, households, were selected using systematic random sampling. All the households in each cluster were serially numbered. To get the sampling interval, the total number of households in a cluster was divided by the sample size of 21 . The first household was then randomly selected by picking any number within the sample interval. Subsequent selections were made by adding the sampling interval to the selected number in order to locate the next household to visit. If the selected household does not have a target respondent, then next household was selected using the systematic sampling procedure. This process continued until the required sample size was obtained. A total of 20 eligible respondents, one per household were selected from each cluster.

\section{Data collection}

A pretested structured interview questionnaire adapted from JHPIEGO, monitoring BPACR ${ }^{11}$ was used for data collection. Using face-to-face interviews with respondents in their houses data were collected on socio-demographic characteristics, reproductive history, pregnancy complications, knowledge of danger signs and BPACR.

\section{Study variables}

The primary outcome measure was BPACR. A brief description of the measurement of key study variables is as follows:

\section{Measurement of BPCR}

In this study, BPACR was defined as a woman having fulfilled at least three of the following practices in the most recent pregnancy: identified health facility for place of delivery, saved money for the purpose of pregnancy and childbirth, decided to deliver by skilled provider, made advance arrangement for transport to skilled care health facility in case of emergency and had made provision for delivery kit/materials. A woman who planned for birth in less than three of the five components was classified as 'not adequately birth prepared and ready for complication'.

\section{Socio-economic and demographic factors}

Socio-economic and demographic information was collected on mothers' age, ethnicity, religion, marital status, parity and highest level of education attained by the mothers. Household wealth index was used as proxy measure of household socio-economic status (SES). Using the principal components analysis method, ${ }^{22}$ the SES of the sampled households was calculated by considering 
specific variables such as: source of drinking water, toilet facility, flooring of the house, roofing, walls and ownership of the household assets (eg, electricity, bicycle, television and radio). Household wealth index was classified as low (that is less than median score) and high (at least median score).

\section{Assessment of obstetric danger signs}

Problems with a pregnancy assessed in this study were bleeding, headache, swelling of feet, hands and face; pallor, fever, abdominal pain and vomiting too much. The major danger signs of labour were severe vaginal bleeding, prolonged labour, convulsions and retained placenta. ${ }^{11}$ Severe vaginal bleeding, foul-smelling vaginal discharge and high fever during the first 7 days after childbirth were considered as key danger signs of the postpartum period. ${ }^{11}$ For danger signs of neonates we considered convulsion, difficult/fast breathing, very small baby, lethargy/unconsciousness and unable to suck/drink during first 7 days of life. ${ }^{12}$ Women who were able to mention at least three of each type of danger signs were classified to be knowledgeable in that area.

\section{Assessment of frequency and content of ANC services}

The frequency of antenatal care (ANC) visits was assessed by asking study participants how often they patronised prenatal care services during pregnancy. ANC visits of less than four were classified as adequate while at least four visits were regarded as adequate attendance. The content of care received during ANC visits was assessed by asking study participants whether specific services including taking of weight and height, measurement of blood pressure and taking blood or urine samples were carried out for them during ANC visits. A composite index comprising 10 of these essential services received during ANC was created by assigning a score of 1 for having received a particular service and 0 for not receiving the service. The services were: measurement of blood pressure in the first, second and third trimesters (1 mark for each assessment), height and weight in the first trimester (1 score for each); examination of urine and blood taken (2 marks), received tetanus toxoid injection given at least one time (1 mark), woman attended at least three health and nutrition education sessions (1 score), received at least two doses of sulfadoxine and pyrimethamine taken in the presence of a health worker (1 score), measurement of fundal height against the age of gestation, fetal heart beat and fetal movement count monthly ( 1 score).

The mean and maximum scores were 6 and 10, respectively. Scores in the range of $0-5$ were classified as 'poor content and, of 6-10, as 'good content'.

\section{Data quality control measures}

To ensure the quality or validity of data collected, six field research assistants and two supervisors were trained and used for the data collection. The research assistants were carefully recruited based on their experience in previous studies. During the training, the research assistants were taken through the questionnaire, sampling techniques and anthropometric measurement. Before the commencement of the actual data collection, the questionnaire was pretested to identify gaps and ability of the tool to collect the desired information.

Data were checked for incompleteness, inconsistency at both field and office levels. Each data collector checked the questionnaires for completeness before leaving each study participant. The questionnaire was reviewed daily by supervisors.

\section{Data analysis}

The analysis of data considered the complex design of multi-stage cluster surveys. Therefore, the data were coded for statistical analysis using SPSS Complex Samples module for windows V.18.0. This was done in order to make statistically valid population inferences and computed SEs from sample data. Design weights were added to each region (ie, total population divided by number of respondents) to perform weighted analysis.

The association between dependent variables and independent variables was determined using multivariable logistic regressions modelling, which included all potential socio-economic, and demographic confounders that were significant at $p$ values $<0.05$ in the bivariate analysis. The associations between the dependent and each independent variable were presented as adjusted ORs (AOR) with $95 \%$ CIs. A CI was considered statistically significant when the interval between the upper and lower values did not include one.

\section{Patient and public involvement}

The current study did not involve patients and/or public.

\section{RESULTS}

\section{Socio-demographic characteristics of study participants}

The distribution of socio-demographic characteristics of study participants are shown in table 1 . The mean age of the respondents was $25.8 \pm 5.9$ years with the minimum and maximum ages of 16 and 45 years, respectively, and $48.8 \%$ of them were under 25 years of age.

Majority $(89.8 \%)$ of the respondents were Christians with only $3.0 \%$ being Moslems. About half $(50 \%)$ of the respondents were of the Kassena tribe. One-third (33\%) of the respondents have basic (primary or JHS) education with $28 \%$ of them having no formal education. Nearly $90 \%$ of the respondents were married and farming and trading were the main sources of income.

\section{Utilisation of antenatal care services}

Almost all (99.7\%) of the women interviewed had received ANC at least one time from a skilled provider during their last pregnancy. More than half $(56.0 \%)$ of the ANC attendees initiated ANC attendance in the first trimester of pregnancy. Almost 9 in 10 (87.0\%) women had four or more ANC visits during the last pregnancy as recommended by the WHO. Of the 600 deliveries 
Table 1 Socio-demographic characteristics of respondents

\begin{tabular}{lll}
\hline Characteristic & Frequency (n) & $\%$ \\
\hline Age groups (years) & & \\
\hline Under 25 years & 293 & 48.8 \\
\hline 25-34 years & 237 & 39.5 \\
\hline At least 35 years & 70 & 11.7 \\
\hline Total & 600 & 100.0 \\
\hline Educational level & & \\
\hline No education & 170 & 28.3 \\
\hline Primary school & 199 & 33.2 \\
\hline Junior High School (JHS) & 162 & 27.0 \\
\hline Secondary school & 64 & 10.7 \\
\hline Tertiary & 5 & 0.8 \\
\hline Total & 600 & 100.0 \\
\hline Religion & & 89.8 \\
\hline Christianity & 539 & 3.0 \\
\hline Islam & 18 & 7.2 \\
\hline African traditional religion & 43 & 100.0 \\
\hline Total & 600 & \\
\hline
\end{tabular}

Marital status

\begin{tabular}{|lll|}
\hline Single & 56 & 9.3 \\
\hline Married & 539 & 89.8 \\
\hline Divorced & 5 & 0.8 \\
\hline Total & 600 & 100.0 \\
\hline Main occupation of mother & & \\
\hline None & 181 & 30.2 \\
\hline Self-employment & 412 & 68.7 \\
\hline Salary worker & 7 & 1.2 \\
\hline Total & 600 & 100.0 \\
\hline Ethnicity & & \\
\hline Buli & 12 & 2.0 \\
\hline Kassena & 302 & 50.3 \\
\hline Nankana & 281 & 46.8 \\
\hline Other & 5 & 0.8 \\
\hline Total & 600 & 100 \\
\hline
\end{tabular}

recorded, $84.3 \%$ were conducted in health institutions with about $85.0 \%$ of the deliveries conducted by a skilled provider (table 2).

\section{Levels of birth preparedness and complication readiness}

BPACR practices by respondents were generally unsatisfactory. Only $30.5 \%$ of the respondents had identified a health facility to go during delivery or in case of complications. Arrangement for transport in case of labour or complications during labour was reported in less than $18 \%$ and $32.7 \%$ of respondents reported having saved money towards delivery of the newborn. The most common birth preparedness practice observed was buying of antiseptics and clothes (74.8\%). However,
Table 2 Utilisation of antenatal care (ANC) services

\begin{tabular}{|c|c|c|}
\hline Variable & Frequency (n) & $\%$ \\
\hline \multicolumn{3}{|l|}{ Frequency of ANC visits } \\
\hline Less than 4 & 50 & 8.3 \\
\hline At least 4 & 517 & 86.2 \\
\hline Do not know & 33 & 5.5 \\
\hline Total & 600 & 100.0 \\
\hline \multicolumn{3}{|c|}{ Gestation of pregnancy at first ANC } \\
\hline Beyond first trimester & 250 & 41.7 \\
\hline Within first trimester & 336 & 56.0 \\
\hline Do not Know & 14 & 2.3 \\
\hline Total & 600 & 100.0 \\
\hline \multicolumn{3}{|l|}{ Place of delivery } \\
\hline Home & 94 & 15.7 \\
\hline Institutional & 506 & 84.3 \\
\hline \multicolumn{3}{|c|}{ Presence of SBA at delivery } \\
\hline Skilled & 509 & 84.8 \\
\hline Unskilled & 91 & 15.2 \\
\hline Total & 600 & 100.0 \\
\hline
\end{tabular}

only $74(12.3 \%)$ of them mentioned identifying skilled provider as way of preparing for birth and its complications. Of the five birth preparedness practices considered in this study, only $14.7 \%$ of respondents were classified as adequately birth prepared (table 3 ).

\section{Factors associated with birth preparedness and complication readiness}

Table 4 shows the association between selected sociodemographic and obstetric characteristics with adequate birth preparedness. The main independent predictors of adequate birth preparedness were maternal knowledge of at least three danger signs of pregnancy and newborn danger signs. Women who had no formal education or up to primary education were less likely to be adequately prepared than women who had attained educational level above primary level $(\mathrm{p}=0.002)$. Women with adequate BPACR were mostly married $(\mathrm{p}=0.001)$.

Multivariable logistic regression was used to adjust for confounders including age, marital status, education, occupation, household wealth index, frequency and content of ANC visits, gestational age at first ANC and knowledge of obstetric danger signs during pregnancy. After adjusting for confounding effects, factors associated with BPACR are shown in table 5.

Mothers with better knowledge about obstetric danger signs during pregnancy were more likely to have adequate birth preparedness (AOR=4.88 (95\% CI: 2.68 to 8.90)). Surprisingly, women who received lower content of ANC services were 3.3 times more likely to have adequate birth preparedness, compared with women who received high content of ANC services (AOR=3.34 (95\% CI: 1.69 to $6.60)$ ). 
Table 3 Birth preparedness and complication readiness (BPACR)

\begin{tabular}{lll}
\hline & \multicolumn{2}{l}{ Frequency } \\
& (n) & $\%$ \\
\hline Identified a trained birth attendant & & \\
\hline No & 526 & 87.7 \\
Yes & 74 & 12.3 \\
\hline Total & 600 & 100.0 \\
\hline Identified a health facility & & \\
\hline No & 417 & 69.5 \\
\hline Yes & 183 & 30.5 \\
\hline Total & 600 & 100.0 \\
\hline Arranged for transport & & \\
\hline No & 493 & 82.2 \\
\hline Yes & 107 & 17.8 \\
\hline Total & 600 & 100.0 \\
\hline Saved money & & \\
\hline No & 404 & 67.3 \\
\hline Yes & 196 & 32.7 \\
\hline Total & 600 & 100.0 \\
\hline Bought antiseptics and clothes & & \\
\hline No & 151 & 25.2 \\
\hline Yes & 449 & 74.8 \\
\hline Total & 600 & 100.0 \\
\hline Adequate (met $\geq 3$ preparations) & 88 \\
\hline
\end{tabular}

Women who had attained educational level above primary level were 3.40 times more likely to be adequately prepared than women who had no formal education or up to primary education $(\mathrm{AOR}=3.40$ (95\% CI: 1.88 to $6.15)$. Women who were classified as having low household wealth index were 4.6 times more likely to have adequate birth preparedness, compared with women of high household wealth index $(\mathrm{AOR}=4.64$ (95\% CI: 1.97 to 10.91$)$ ). Older women ( $\geq 35$ years) were 2.59 times more likely to have adequate birth preparedness than their colleagues who were under 25 years $(\mathrm{AOR}=2.59$ (95\% CI: 1.11 to 6.02$)$ ).

\section{DISCUSSION}

Though the benefits of BPACR have been documented in several countries, little or no information is currently available on levels of BPACR in Ghana and specifically in Upper East Region. This study therefore assessed BPACR and associated factors in the Kassena-Nankana district of Ghana.

\section{Prevalence of BPACR}

One of the main findings that emerged from this study is that less than $15 \%$ of the mothers were adequately prepared for delivery and complication readiness. The poor BPACR practices reported in our study corroborated with the findings of an earlier study conducted in Southern Ghana which showed the proportion of wellprepared pregnant women was $19 \% .^{23}$ Similar studies conducted in Ghana further revealed that most pregnant women go for delivery unprepared though they may have knowledge about BPACR. ${ }^{24}{ }^{25}$ The finding is also consistent with other studies conducted elsewhere including Nigeria, Ethiopia and Tanzania, ${ }^{20} 26$ where BPACR practices were poor among rural women.

The low proportion of adequate BPACR suggests that education on birth preparedness and complications is not being given during ANC since majority of the respondents $(86.2 \%)$ had attended at least four ANC visits during their last pregnancy.

Inadequate BPACR has the potential to adversely affect the maternal and child health outcomes, as women will be ill-prepared to use skilled birth attendants at delivery or respond to complications in a timely manner.

Implementation of a BPACR programme should therefore be an essential part of antenatal education to increase the BPACR rate above the existing result, since BPACR intervention can increase preparation for birth and complications. ${ }^{28}$

Most pregnant women are reported not knowledgeable about BPACR for obstetric emergencies, despite having awareness on the danger signs of pregnancy. ${ }^{29-31}$

As reported in other studies, ${ }^{32} 33$ the most common birth preparedness practice observed in our study was buying antiseptics and clothes. However, studies conducted in Burkina Faso and in Ethiopia however, found that most women had identified skilled birth attendants and health facility as the main birth preparedness practices. ${ }^{345}$

\section{Factors associated with adequate BPACR}

In this study, women who knew and could mention at least three pregnancy danger signs were five times more likely to have adequate birth preparedness. It is expected that knowledge of danger signs leads to greater anticipation and preparation to mitigate effects of pregnancy and childbirth complications by preventing delay in deciding to seek care and delay in reaching a health facility.

The recognition of obstetric danger signs is a push factor among pregnant women to seek healthcare for obstetric emergencies and seeking preventive care or health promotion during pregnancy and childbirth. Naturally, a lack of awareness of obstetric danger signs will be associated with inadequate preparedness for normal birth or complication readiness. ${ }^{10} 36$

The positive association between knowledge of key danger signs during pregnancy or during the postpartum period with birth preparedness among women has been reported in earlier studies. ${ }^{32}{ }^{37-41}$ A lack of awareness of obstetric danger signs may thus lead to a lack of preparedness for normal birth or complication readiness in case of obstetric complications that require emergency healthcare. ${ }^{42} 43$ 
Table 4 Association between selected socio-demographic and obstetric characteristics and birth preparedness and complication readiness (bivariate analysis)

\begin{tabular}{|c|c|c|c|c|}
\hline \multirow[b]{2}{*}{ Variable } & \multirow[b]{2}{*}{$\mathbf{N}$} & \multicolumn{2}{|c|}{ Adequately birth prepared? } & \multirow[b]{2}{*}{ Test statistic } \\
\hline & & No, $n(\%)$ & Yes, n (\%) & \\
\hline \multicolumn{5}{|l|}{ Educational level } \\
\hline Low (up to primary level) & 369 & $328(88.9)$ & $41(11.1)$ & \multirow[t]{2}{*}{$\chi^{2}=9.6, p=0.002$} \\
\hline High (above primary level) & 231 & $184(79.7)$ & $47(20.3)$ & \\
\hline \multicolumn{5}{|l|}{ Marital status } \\
\hline Single & 61 & $60(98.4)$ & $1(1.6)$ & \multirow[t]{2}{*}{ Fisher's exact test $=9.2, p=0.001$} \\
\hline Married & 539 & $452(83.9)$ & $87(16.1)$ & \\
\hline \multicolumn{5}{|l|}{ Antenatal care content } \\
\hline Low & 60 & $42(70.0)$ & $18(30.0)$ & \multirow[t]{2}{*}{$\chi^{2}=12.4, p<0.001$} \\
\hline High & 538 & $468(87.0)$ & $70(13.0)$ & \\
\hline \multicolumn{5}{|l|}{ Household wealth index } \\
\hline Low & 482 & $401(83.2)$ & $81(16.8)$ & \multirow[t]{2}{*}{$\chi^{2}=9.0, p=0.003$} \\
\hline High & 118 & $111(94.1)$ & $7(5.9)$ & \\
\hline \multicolumn{5}{|c|}{ Knowledge of 3 danger signs during pregnancy } \\
\hline No & 382 & $343(89.8)$ & $39(10.2)$ & \multirow[t]{2}{*}{$\chi^{2}=16.7, p<0.001$} \\
\hline Yes & 218 & $169(77.5)$ & $49(22.5)$ & \\
\hline \multicolumn{5}{|c|}{ Knowledge of 3 newborn danger signs } \\
\hline No & 282 & $267(94.7)$ & $15(5.3)$ & \multirow[t]{2}{*}{$\chi^{2}=37.1, p<0.001$} \\
\hline Yes & 318 & $245(77.0)$ & $73(23.0)$ & \\
\hline
\end{tabular}

Low awareness of danger signs coupled with inadequate birth preparedness can significantly contribute to the delay in seeking skilled care. From the evidence provided in this and other studies, a comprehensive sustainable education should be given to mothers during antenatal sessions on BPACR by community-level health service

Table 5 Factors associated with birth preparedness and complication readiness (multivariable regression analysis)

\begin{tabular}{|c|c|c|c|c|}
\hline Variable & Wald & Sig. & Adjusted OR & $95 \% \mathrm{Cl}$ \\
\hline \multicolumn{5}{|l|}{ Educational level } \\
\hline Low (up to primary level) & Reference & Reference & Reference & Reference \\
\hline High (above primary level) & 16.32 & $<0.001$ & 3.40 & 2.88 to 6.15 \\
\hline \multicolumn{5}{|l|}{ Age of mother (years) } \\
\hline Under 25 & Reference & Reference & Reference & Reference \\
\hline $25-34$ & 0.22 & 0.64 & 1.15 & 0.65 to 2.03 \\
\hline At least 35 & 4.92 & 0.03 & 2.59 & 1.12 to 6.02 \\
\hline \multicolumn{5}{|c|}{ Classification of household wealth index } \\
\hline High & Reference & Reference & Reference & Reference \\
\hline Low & 12.35 & $<0.001$ & 4.64 & $\begin{array}{l}1.97 \text { to } \\
10.91\end{array}$ \\
\hline \multicolumn{5}{|c|}{ Knowledge of least 3 pregnancy danger signs } \\
\hline No & Reference & Reference & Reference & Reference \\
\hline Yes & 26.71 & $<0.001$ & 4.88 & $\begin{array}{l}2.68 \text { to } \\
8.90\end{array}$ \\
\hline \multicolumn{5}{|l|}{ Antenatal care content } \\
\hline High & Reference & Reference & Reference & Reference \\
\hline Low & 12.06 & 0.001 & 3.34 & $\begin{array}{l}1.69 \text { to } \\
6.60\end{array}$ \\
\hline
\end{tabular}


providers. Steps should also be taken to raise community awareness about birth preparedness, such as having plans to deliver in health facilities and arrangement for emergency transport.

However, other studies conducted in Ethiopia and in India found no significant association between key danger signs and birth preparedness after multivariate analyses. ${ }^{44} 45$

One other independent predictor of adequate birth preparedness was content of ANC services received which surprisingly was negatively associated with adequate BPACR. Women who received lower content of ANC services were 3.3 times more likely to have adequate birth preparedness, compared with women who received high content of ANC services. A possible explanation may be that women who received higher content were less knowledgeable in obstetric danger signs of pregnancy. Though women may have received sufficient ANC services, education on the danger signs during pregnancy could have been overlooked by service providers. A number of studies have indeed reported of the poor or inadequate education on danger signs provided by midwives to mothers who seek ANC services in eastern Uganda. ${ }^{46}$

In this study and in others, attendance of ANC of four or more times was not associated with being well birth prepared in the present study ${ }^{37}$ though results of some studies showed that having frequent access to ANC services positively associated with BPACR. ${ }^{20} 39$ 48-52

ANC attendance gives an opportunity for a woman to be counselled and make an appropriate plan for childbirth. ${ }^{53}$ It is therefore expected that pregnant women who frequently attend ANC sessions will be more likely to be prepared for birth and its complications than those who do not attend ANC. This assumption will hold if educational lessons are given to women at ANC. In the absence of that, ANC attendance will not associate with BPACR as observed in this study. Indeed, one recent study in southwest Ethiopia reported that three-fourth of pregnant women were not counselled on all components of BPACR. ${ }^{33}$ Therefore, it is possible that an increase in frequency of ANC visits per se may not result in better BPCR. Increased BPCR awareness in women could be promoted by healthcare workers during ANC visits

The results of the present study showed that women who were classified as having low household wealth index were 4.6 times more likely to have adequate birth preparedness, compared with women of high household wealth index. In meeting the key components of BPACR, those that have implication for money may have to do with saving money for the purpose of pregnancy and childbirth and perhaps buying delivery kit/materials. All things being equal, one would expect that women of high household wealth index will rather find it easy to meet BPACR but the opposite appears to have happened in our study sample.

This might be due to the fact that rich women might not see the need to plan for certain practices like pre-identifying a health facility or skilled birth attendant because of their perceived ability to access any health facility including private ones which might be expensive to the poor. It is also possible that rich women may have their own means of transport and so will not plan for transportation. In this case, they are most likely be classified as not being prepared for transport arrangement, and this will affect their overall BPACR score. Such a situation can therefore confound the relationship between wealth and BPACR. This study was conducted among women who have recently delivered and have experienced all these practices, compared with pregnant women who may not be sure of what would actually occur towards the time of delivery.

Our finding is however, inconsistent with that of other studies where women in the third, fourth or fifth wealth quintiles were more likely to be prepared as compared with women in the lowest quintiles. ${ }^{33} 495455$ This means the odds of being well prepared for birth and its complications was significantly higher among women from high SES than those from low SES. In this case, the likely reasons could be that rich women having high income will be enabled to prepare for birth and its complications. In a recent study in Ghana, it was reported that most of the respondents were not sufficiently prepared for delivery due to poverty and low educational status. ${ }^{56}$

This study also observed that women who had attained educational level above primary level were 3.4 times more likely to be adequately prepared than women who had no formal education or only up to primary school level. This observation is in consonance with findings of similar studies where educational level was found to be positively and significantly associated with BPACR. ${ }^{5455} 5758$

Higher educational achievement has been shown to positively influence women with regards to positive health seeking behaviour including increased utilisation of maternal health services. ${ }^{59-62}$ This might be related to the fact that educated women have decision-making power to make their own decisions in matters related to their health and are most likely to have fewer financial constraints in accessing healthcare.

In this study population, older women ( $\geq 35$ years) were 2.6 times more likely to have adequate birth preparedness than their colleagues who were under 25 years of age. This finding is consistent with other studies. ${ }^{63} \mathrm{~A}$ possible explanation for this relationship may be that older women would have experienced complications on their previous pregnancies, thereby trying to prevent any such problems for the current pregnancy. However, some studies reported that younger women ( $<35$ years) had higher odds of BPCR practice than women above 35 years of age. ${ }^{64-66}$

In some studies BPACR status was not significantly associated with maternal age ${ }^{47}$

\section{Limitations of the study}

There are some limitations of the study which need to be considered. The analytical cross-sectional study design limits the ability to draw any causal conclusions since the problem of bias cannot be ruled out completely. 


\section{CONCLUSION}

The prevalence of BPACR among recently delivered women was low as less than $15 \%$ were able to mention at least three of the five basic components of BPCR. Though knowledge of obstetric danger signs was equally low, it associated positively with BPACR. These findings lend support to reinforce health education on BPACR during pregnancy. Further implication of the findings is that the predictors identified should be given high priority by health authorities in addressing low prevalence of BPACR.

Acknowledgements The authors wish to acknowledge the cooperation of the study mothers and the community health volunteers during the data collection. Sincere thanks also go to members of the Kassena-Nankana District Health Directorate for their support.

Contributors LA wrote the proposal, participated in data collection and analysis. MS made some revisions on proposal, participated in data analysis and wrote the manuscript. Both authors reviewed, revised and approved the manuscript for publication.

Funding The authors have not declared a specific grant for this research from any funding agency in the public, commercial or not-for-profit sectors.

Competing interests None declared.

Patient and public involvement Patients and/or the public were not involved in the design, or conduct, or reporting, or dissemination plans of this research.

Patient consent for publication Not required.

Ethics approval The study protocol was approved by the School of Allied Health Sciences, University for Development Studies, Ghana. Ethical clearance was obtained from the Institutional Review Board of the Tamale Teaching Hospital, Ghana (Ref no. TTH/10/11/15/02). Informed written consent was obtained from the literate participants. In situations, where the participants could not write or read, verbal informed consent was sought after providing the needed information and explanation.

Provenance and peer review Not commissioned; externally peer reviewed.

Data availability statement All data relevant to the study are included in the article or uploaded as supplemental information.

Open access This is an open access article distributed in accordance with the Creative Commons Attribution Non Commercial (CC BY-NC 4.0) license, which permits others to distribute, remix, adapt, build upon this work non-commercially, and license their derivative works on different terms, provided the original work is properly cited, appropriate credit is given, any changes made indicated, and the use is non-commercial. See: http://creativecommons.org/licenses/by-nc/4.0/.

ORCID iD

Mahama Saaka http://orcid.org/0000-0003-0295-0328

\section{REFERENCES}

1 World Health Organization. Trends in maternal mortality: 2000 to 2017: estimates by who, UNICEF, UNFPA, the world bank and the United nations population division: Executive summary. Geneva: World Health Organization, 2019.

2 Hogan MC, Foreman KJ, Naghavi M, et al. Maternal mortality for 181 countries, 1980-2008: a systematic analysis of progress towards millennium development goal 5. Lancet 2010;375:1609-23.

3 Bongaarts J, United Nations Population Division, WHO, UNICEF, UNFPA, World Bank Group, United Nations Population Division. Trends in maternal mortality: 1990 to 2015 population and development review 2015;42:726-26.

4 Alkema L, Chou D, Hogan D, et al. Global, regional, and national levels and trends in maternal mortality between 1990 and 2015, with scenario-based projections to 2030: a systematic analysis by the un maternal mortality estimation Inter-Agency group. Lancet 2016;387:462-74.

5 Say L, Chou D, Gemmill A, et al. Global causes of maternal death: a who systematic analysis. Lancet Glob Health 2014;2:e323-33.

6 WHO, UNICEF, UNFPA, The World Bank. Trends in maternal mortality: 1990 to 2010. Geneva, Switzerland: World Health Organization, UNICEF, UNFPA and The World Bank, 2010.
7 Thaddeus S, Maine D. Too far to walk: maternal mortality in context. Soc Sci Med 1994;38:1091-110.

8 JHIPEGO. Maternal and Neonatal Health (MNH) Program. Birth preparedness and complication readiness: a matrix of shared responsibilities. secondary maternal and neonatal health $(\mathrm{MNH})$ program. birth preparedness and complication readiness: a matrix of shared responsibilities 2001.

9 Hussein J, Kanguru L, Astin M, et al. The effectiveness of emergency obstetric referral interventions in developing country settings: a systematic review. PLoS Med 2012;9:e1001264.

10 Graham W, Themmen E, Bassane B, et al. Evaluating skilled care at delivery in Burkina Faso: principles and practice. Trop Med Int Health 2008;13 Suppl 1:6-13.

11 JHPIEGO, Maternal and Neonatal Health Program. Monitoring Birth preparedness and complication readiness, tools and indicators for maternal and newborn health. Baltimore, MD: Johns Hopkins, Bloomberg school of Public Health, Center for communication programs, Family Care International, 2004: 1-19.

12 Stanton CK. Methodological issues in the measurement of birth preparedness in support of safe motherhood. Eval Rev 2004;28:179-200.

13 Mikki N, Abdul-Rahim HF, Stigum H, et al. Anaemia prevalence and associated sociodemographic and dietary factors among Palestinian adolescents in the West bank. East Mediterr Health $J$ 2011;17:208-17.

14 Halileh S, Gordon NH. Determinants of anemia in pre-school children in the occupied Palestinian Territory. J Trop Pediatr 2006;52:12-18.

15 McDonald CM, McLean J, Kroeun H, et al. Household food insecurity and dietary diversity as correlates of maternal and child undernutrition in rural Cambodia. Eur J Clin Nutr 2015;69:242-6.

16 WHO. Worldwide prevalence of anemia 1993-2005: who global database on anemia. Geneva, Switzerland: World Health Organization, 2008.

17 Leal LP, Filho MB, de Lira PIC, et al. Prevalence of anemia and associated factors in children aged 6-59 months in Pernambuco, northeastern Brazil. Revista de Saúde Pública 2011;45:457-66.

18 Osório MM, Lira PIC, Ashworth A. Factors associated with $\mathrm{Hb}$ concentration in children aged 6-59 months in the state of Pernambuco, Brazil. Br J Nutr 2004;91:307-14.

19 Soubeiga D, Gauvin L, Hatem MA, et al. Birth preparedness and complication readiness (BPCR) interventions to reduce maternal and neonatal mortality in developing countries: systematic review and meta-analysis. BMC Pregnancy Childbirth 2014;14:1-11.

20 Hailu M, Gebremariam A, Alemseged F, et al. Birth preparedness and complication readiness among pregnant women in southern Ethiopia. PLoS One 2011;6:e21432.

21 Omari PK, Afrane YA, Ouma P. Birth preparedness and complication readiness among women attending antenatal care clinic in health facilities within Bureti sub County of Kericho County, Kenya. American JMMS 2016;6:123-8.

22 Filmer D, Pritchett LH. Estimating wealth effects without expenditure data--or tears: an application to educational enrollments in states of India. Demography 2001;38:115-32.

23 Wurapa AR, Abudey S, Ankomah A, et al. Birth preparedness and complication readiness among pregnant women in Hohoe Municipality of Ghana. IJNRHN 2016;3:93-104.

24 Suglo S, Siakwa M. Knowledge and practices on birth preparedness among expectant mothers seeking antenatal care at the Tamale teaching Hospital, Ghana. International Journal of Research in Medical and Health Sciences 2016:8:1-10.

25 Lori JR, Dahlem CHY, Ackah JV, et al. Examining antenatal health literacy in Ghana. J Nurs Scholarsh 2014;46:432-40.

26 Ibadin SH, Adam VY, Adeleye OA, et al. Birth preparedness and complication readiness among pregnant women in a rural community in southern Nigeria. S Afr J Obstet Gynaecol 2016;22:47-51.

27 Urassa DP, Pembe AB, Mganga F. Birth preparedness and complication readiness among women in Mpwapwa district, Tanzania. Tanzan J Health Res 2012;14:42-7.

28 Solnes Miltenburg A, Roggeveen Y, Shields L, et al. Impact of birth preparedness and complication readiness interventions on birth with a skilled attendant: a systematic review. PLoS One 2015;10:e0143382.

29 Ekesa BN, Blomme G, Garming H. Dietary diversity and nutritional status of pre-school children from Musa-dependent households in Gitega (Burundi) And Butembo (Democratic Republic Of Congo). African Journal of Food, Agriculture, Nutrition and Development 2011;11.

30 Khoushabi F, Saraswathi G. Impact of nutritional status on birth weight of neonates in Zahedan City, Iran. Nutr Res Pract 2010;4:339.

31 Muthayya S. Maternal nutrition \& low birth weight - what is really important? Indian J Med Res 2009;130:600-8. 
32 Kabakyenga JK, Östergren PO, Turyakira E, et al. Knowledge of obstetric danger signs and birth preparedness practices among women in rural Uganda Reprod health 2011;8:e33.

33 Letose F, Admassu B, Tura G. Birth preparedness, complication readiness and associated factors among pregnant women in Agnuak zone, Southwest Ethiopia: a community based comparative crosssectional study. BMC Pregnancy Childbirth 2020;20:e72.

34 Adish AA, Esrey SA, Gyorkos TW, et al. Risk factors for iron deficiency anaemia in preschool children in northern Ethiopia. Public Health Nutr 1999;2:243-52.

35 Lawless JW, Latham MC, Stephenson LS, et al. Iron supplementation improves appetite and growth in anemic Kenyan primary school children. J Nutr 1994;124:645-54

36 Pembe AB, Carlstedt A, Urassa DP, et al. Effectiveness of maternal referral system in a rural setting: a case study from Rufiji district, Tanzania. BMC Health Serv Res 2010;10:e326.

37 Agho KE, Dibley MJ, D'Este C, et al. Factors associated with haemoglobin concentration among Timor-Leste children aged 6-59 months. J Health Popul Nutr 2008;26:200-9.

38 Arimond M, Wiesmann D, Becquey E, et al. Simple food group diversity indicators predict micronutrient adequacy of women's diets in 5 diverse, resource-poor settings. J Nutr 2010;140:2059S-69.

39 Bishaw W, Awoke W, Teshome M. Birth preparedness and complication readiness and associated factors among PregnantWomen in Basoliben district, Amhara regional state, Northwest Ethiopia. Primary Health Care 2014;4:e171.

40 Mbalinda SN, Nakimuli A, Kakaire O, et al. Does knowledge of danger signs of pregnancy predict birth preparedness? A critique of the evidence from women admitted with pregnancy complications. Health Res Policy Syst 2014;12:e60.

41 Zepre K, Kaba M. Birth preparedness and complication readiness among rural women of reproductive age in Abeshige district, Guraghe zone, SNNPR, Ethiopia. Int J Womens Health 2017;9:11-21.

42 Brinkman H-J, de Pee S, Sanogo I, et al. High food prices and the global financial crisis have reduced access to nutritious food and worsened nutritional status and health. J Nutr 2010;140:153S-61.

43 FAO. Guidelines for measuring household and individual dietary diversity. Version 3 Rome, Italy. Rome, Italy: Food and Agriculture Organization, 2007.

44 Ngure FM, Reid BM, Humphrey JH, et al. Water, sanitation, and hygiene (wash), environmental enteropathy, nutrition, and early child development: making the links. Ann N Y Acad Sci 2014;1308:118-28.

45 WHO. Nutrition landscape information system (NLIS) country profile indicators: interpretation guide. Geneva, Switzerland: World Health Organization, 2010.

46 Wen L, Flood VM, Simpson JM, et al. Dietary behaviours during pregnancy: findings from first-time mothers in Southwest Sydney, Australia. Int J Behav Nutr Phys Act 2010;7:13-17.

47 Mandal T, Biswas R, Bhattacharyya S, et al. Birth Preparedness and Complication Readiness Among Recently Delivered Women in a Rural Area of Darjeeling,West Bengal,India. AMSRJ 2015;2:14-20.

48 Teekhasaenee T, Kaewkiattikun K. Birth preparedness and complication readiness practices among pregnant adolescents in Bangkok, Thailand. Adolesc Health Med Ther 2020;11:1-8.

49 Andarge E, Nigussie A, Wondafrash M. Factors associated with birth preparedness and complication readiness in southern Ethiopia: a community based cross-sectional study. BMC Pregnancy Childbirth 2017;17:e412.

50 Markos D, Bogale D. Birth preparedness and complication readiness among women of child bearing age group in Goba woreda, Oromia region, Ethiopia. BMC Pregnancy Childbirth 2014;14:E282.
51 Kaso M, Addisse M. Birth preparedness and complication readiness in Robe Woreda, Arsi zone, Oromia region, central Ethiopia: a crosssectional study. Reprod Health 2014;11:e55.

52 Obi Al. Birth preparedness and complication readiness: attitude and level of preparedness among pregnant women in Benin City, Edo state, Nigeria. Br J Med Med Res 2016;15:1-14.

53 World Health Organization, editor. Mother-baby package: implementing safe motherhood in countries, practical guide. Geneva: Whqlibdoc.Who.Int, 1994.

54 Debelew GT, Afework MF, Yalew AW. Factors affecting birth preparedness and complication readiness in Jimma zone, Southwest Ethiopia: a multilevel analysis. Pan Afr Med J 2014;19:e272.

55 Sharma N, Kumar N, Singh S, et al. Status and determinants of birth preparedness and complication readiness in a rural block of Haryana. J Family Med Prim Care 2019;8:482-6.

56 Konlan KD, Japiong M, Konlan KD. Pregnant Women's experiences of Birth Preparedness and Complication Readiness in Ghana. Journal of midwifery and reproductive health 2019;7:1644-54.

57 Kiataphiwasu N, Kaewkiattikun K. Birth preparedness and complication readiness among pregnant women attending antenatal care at the faculty of medicine Vajira Hospital, Thailand. Int $J$ Womens Health 2018;10:797-804.

58 Tobin EA, Ofili AN, Nkemka E, et al. Assessment of birth preparedness and complication readiness among women attending primary health care centres in Edo state, Nigeria. Ann Nigerian Med 2014;8:76-81.

59 Rai RK, Singh PK, Singh L. Utilization of maternal health care services among married adolescent women: insights from the Nigeria demographic and health survey, 2008. Womens Health Issues 2012;22:e407-14.

60 Ochako R, Fotso J-C, Ikamari L, et al. Utilization of maternal health services among young women in Kenya: insights from the Kenya demographic and health survey, 2003. BMC Pregnancy Childbirth 2011;11:e1

61 Banke-Thomas A, Banke-Thomas O, Kivuvani M, et al. Maternal health services utilisation by Kenyan adolescent mothers: analysis of the demographic health survey 2014. Sex Reprod Healthc 2017;12:37-46.

62 Banke-Thomas O, Banke-Thomas A, Ameh CA. Utilisation of maternal health services by adolescent mothers in Kenya: analysis of the demographic health survey 2008-2009. Int J Adolesc Med Health 2016;30. doi:10.1515/ijamh-2016-0042. [Epub ahead of print: 12 Oct 2016].

63 Akshaya KM, Shivalli S. Birth preparedness and complication readiness among the women beneficiaries of selected rural primary health centers of Dakshina Kannada district, Karnataka, India. PLoS One 2017;12:e0183739.

64 Azeze GA, Mokonnon TM, Kercho MW. Birth preparedness and complication readiness practice and influencing factors among women in Sodo town, Wolaita zone, southern Ethiopia, 2018; community based cross-sectional study. Reprod Health 2019;16:e39.

65 Sabageh AO, Adeoye OA, Adeomi AA, et al. Birth preparedness and complication readiness among pregnant women in Osogbo Metropolis, Southwest Nigeria. Pan Afr Med J 2017;27:e74.

66 Tafa A, Hailu D, Ebrahim J, et al. Birth preparedness and complication readiness plan among antenatal care attendants in Kofale district, South East Ethiopia: a cross sectional survey. Divers Equal Health Care 2018;15:23-9. 